\title{
Arnaud Schmitt, Je réel/je fictif. Au-delà d'une confusion postmoderne
}

\section{Gabriella Bosco}

\section{(2) OpenEdition}

1 Journals

\section{Edizione digitale}

URL: http://journals.openedition.org/studifrancesi/6149

DOI: 10.4000/studifrancesi.6149

ISSN: 2421-5856

\section{Editore}

Rosenberg \& Sellier

\section{Edizione cartacea}

Data di pubblicazione: 1 mai 2011

Paginazione: 233-234

ISSN: 0039-2944

\section{Notizia bibliografica digitale}

Gabriella Bosco, «Arnaud Schmitt, Je réel/je fictif. Au-delà d'une confusion postmoderne», Studi Francesi

[Online], 163 (LV | I) | 2011, online dal 30 novembre 2015, consultato il 08 janvier 2021. URL: http:// journals.openedition.org/studifrancesi/6149; DOI: https://doi.org/10.4000/studifrancesi.6149

Questo documento è stato generato automaticamente il 8 janvier 2021.

\section{(c) (i) (9)}

Studi Francesi è distribuita con Licenza Creative Commons Attribuzione - Non commerciale - Non opere derivate 4.0 Internazionale. 


\title{
Arnaud Schmitt, Je réel/je fictif. Au- delà d'une confusion postmoderne
}

\author{
Gabriella Bosco
}

\section{NOTIZIA}

ARNAUD SCHMITT, Je réel/je fictif. Au-delà d'une confusion postmoderne, Toulouse, Presses

Universitaires du Mirail, 2010, pp. 202.

1 Studioso di Philip Roth e specialista delle forme della narrazione postmoderna, Arnaud SCHMITT affronta in questo volume una questione ormai annosa, al centro del dibattito sulle scritture personali da oltre tre decenni, ovvero dalla nascita ufficiale del genere ibrido che va sotto il nome di autofiction, secondo la definizione di Serge Doubrovsky: la questione delle relazioni che intercorrono tra l'io reale e l'io fittizio. Il punto di vista dell'A. è quello di chi, a partire dalla presa d'atto di una cancellazione dei confini tra i generi narrativi e tra gli statuti del soggetto, tenta di individuare in ambito teorico, e poi nella prassi, delle costanti riconducibili a una lettura univoca delle varie scritture finzionali in prima persona praticate oggi, all'alba del XXI secolo.

Riflessione di partenza del discorso di Arnaud Schmitt è da considerare l'articolo intitolato La perspective de l'autonarration («Poétique», 149, février 2007) nel quale dimostrava la permanenza, ma insieme la fragilità, della distinzione tra finzione e autobiografia nell'era che Nathalie Sarraute ha battezzato come quella del sospetto.

Esaminando le numerose teorie sorte intorno alla categoria dell'autofinzione e a quella di figura dell'autore, la cui morte Roland Barthes ha decretato per permettere l'avvio di una sua rinascita dopo il trattamento depersonalizzante, Arnaud Schmitt sembra voler prendere posizione nel dibattito come colui che, pragmaticamente, ristabilisce una demarcazione principalmente funzionale tra io fittizio e io reale. Proposta, la sua, che comporta una riformulazione del patto lejeuniano alla luce di una teoria della ricezione. Ovvero: a contare non è più un'ipotesi di verificabilità da parte del lettore di una corrispondenza tra racconto scritto dall'autore e fatti da lui vissuti - obsoleta per 
via del nuovo rapporto tra l'uomo e il mondo che il dopo Storia, il dopo genocidio, il dopo bomba $\mathrm{H}$ hanno determinato ineluttabilmente, svuotando di senso i dogmi della rappresentabilità e dell'espressione-bensì il contratto che il lettore stipula simbolicamente con la figura dell'autore ch'egli si è costruito a partire dalla lettura del testo, e eventualmente del paratesto, contratto, patto che, una volta firmato, incarna in sé tutta la realtà del testo e che nelle premesse comporta una ipoteca di fragilità, ma che sostituendosi efficacemente a quello autobiografico di un tempo, è in grado di descrivere e contenere il panorama postmoderno delle scritture in prima persona. 